\title{
Midodrine overdose in children: a case report and review of treatment for hypertensive emergencies
}

\author{
Meryam Jan ${ }^{1}$, Elizabeth Brothers ${ }^{2}$, Thomas A. Nakagawa, \\ ${ }^{1}$ Department of Pediatrics PGY3, University of Florida College of Medicine - Jacksonville, Jacksonville, FL, USA; ${ }^{2}$ Pediatric Critical Care, Wolfson \\ Children's Hospital, Jacksonville, FL, USA; ${ }^{3}$ Department of Pediatrics, Division of Pediatric Critical Care, University of Florida College of Medicine \\ - Jacksonville, Jacksonville, FL, USA; ${ }^{4}$ Division of Pediatric Critical Care Medicine, Wolfson Children's Hospital, Jacksonville, FL, USA \\ Correspondence to: Dr. Meryam Jan, MD. Department of Pediatrics PGY3, University of Florida College of Medicine - Jacksonville, 841 Prudential \\ Drive, Suite 1130, Jacksonville, FL 32207, USA. Email: Meryam.Jan@jax.ufl.edu.
}

\begin{abstract}
Midodrine is an antihypotensive agent used primarily in the adult population for orthostatic hypotension and reflex syncope, postural orthostatic tachycardia syndrome (POTS), and hemodialysisinduced hypotension. Limited information about midodrine ingestion and overdose exists in children with only a single case series reported in the literature. Varying presentations of midodrine ingestion in children have not been shown to be acutely life-threatening in doses up to $50 \mathrm{mg}$. We present a case of a 12 -year-old who intentionally ingested $100 \mathrm{mg}$ of midodrine and presented with a hypertensive emergency and seizure activity. This is the largest reported dose ingested in a child. The patient was observed and treated with a nicardipine infusion in the pediatric intensive care unit (PICU). Prompt identification and treatment of symptoms contributed to a favorable outcome with no neurologic deficits and complete recovery from an intentional ingestion of midodrine. Mechanism, duration of action, and management of midodrine ingestion including treatment for a hypertensive emergency in children are discussed. Commonly used pharmacologic agents to treat hypertension are reviewed. This case report of a significant ingestion of midodrine reviews management of hypertensive emergencies and provides information and guidance to healthcare professionals unfamiliar with this medication and its potentially fatal effects.
\end{abstract}

Keywords: Midodrine; hypertension; overdose; seizure; emergency

Submitted Apr 06, 2021. Accepted for publication Jun 21, 2021.

doi: $10.21037 /$ tp-21-153

View this article at: https://dx.doi.org/10.21037/tp-21-153

\section{Introduction}

Midodrine is a potent peripherally acting alpha-1 agonist most commonly used as an antihypotensive agent in adults for orthostatic hypotension and reflex syncope (1), postural orthostatic tachycardia syndrome (POTS), and hemodialysis-induced hypotension (2). The onset of action is approximately 30 minutes, and half-life is $3-4$ hours (3). Few case reports of midodrine overdose exist $(4,5)$, and of those even fewer are related to children (5). We present a case of a 12-year-old who intentionally ingested midodrine and presented with significant hypertension, in accordance with the CARE reporting checklist (available at https:// dx.doi.org/10.21037/tp-21-153).

\section{Case presentation}

A 12-year-old female with POTS treated with midodrine $10 \mathrm{mg}$ three times daily, presented to the emergency department (ED) following a suicide attempt. She reported intentionally ingesting an estimated $10(10 \mathrm{mg})$ midodrine tablets (total $100 \mathrm{mg}$ ). Initial blood pressure was $170 / 40 \mathrm{mmHg}$ and heart rate was 54 beats per minute with no ectopy. She was afebrile. She was awake and alert and her neurologic examination revealed no focal deficits. She complained of nausea and headache that was treated with ketorolac and ondansetron. Lung fields were clear to auscultation bilaterally, and cardiac examination revealed normal heart tones with 
no murmurs. She was well perfused with a capillary refill time of less than two seconds. Laboratory studies included an unremarkable complete blood count and comprehensive metabolic panel. Salicylate, ethanol, and toxicology panel were negative. Transfer to the pediatric intensive care unit (PICU) for continued monitoring and ongoing management of her hypertension occurred. In the PICU her blood pressure was $165 / 120 \mathrm{mmHg}$ and heart rate was $57 \mathrm{bpm}$. Physical examination was unchanged, and she remained neurologically intact. A nicardipine infusion was prepared to treat her hypertension. During her interview, she acutely developed right lateral gaze eye deviation followed by a tonic-clonic seizure. The seizure subsided with administration of $2 \mathrm{mg}$ of intravenous (IV) lorazepam. During the seizure, she remained lucid and communicated appropriately. A nicardipine infusion was started and titrated to maintain her systolic blood pressure in the range of $120-140 \mathrm{mmHg}$. Nicardipine was gradually weaned off over the next 2 hours as her blood pressure returned to normal. She was observed in the PICU for 24 hours. No further hypertension or seizure activity was noted. Blood pressure measurement confirmed orthostatic hypotension from laying, sitting, and standing. She was restarted on midodrine approximately 24 hours after ingestion and recovered without any neurologic sequelae. She was discharged from the PICU after medical clearance and transferred to the in-patient behavioral health unit. All interventions performed were in accordance with the ethical standards of the institutional committee and with the Helsinki Declaration (as revised in 2013) and after consent was obtained from legal guardian.

\section{Discussion}

Midodrine is a potent peripherally acting alpha-1 agonist that increases peripheral venous resistance. It is commonly used as an antihypotensive agent in adults with orthostatic hypotension and reflex syncope to increase postural blood pressures (1), POTS (as in our patient), and hemodialysis-induced hypotension (5). The onset of action is approximately 30 minutes, and half-life is $3-4$ hours (3). Side effects include compensatory reflex bradycardia, hypertension, and urinary retention $(1,6)$. Metabolism occurs in the gastrointestinal tract, and there is little absorption through the blood-brain barrier in therapeutic doses up to $10 \mathrm{mg}(6)$.

There is only a single case review of five reported toxicology reactions in children less than 16 years of age.
Ingestions ranged from $2-50 \mathrm{mg}$ and showed that infants generally had minor to no symptoms, while a 14 -year-old male developed mild bradycardia and hypertension with a minor poisoning severity score (5). No other pediatric cases are documented in the literature. Seizures secondary to hypertension are known to occur however, the hypertensive encephalopathy with seizure has not been previously reported as a result of midodrine ingestion.

No known antidote exists for midodrine therefore treatment is directed at symptom management. The most common side effects of midodrine are hypertension, reflex bradycardia, and urinary retention. Hypertension can be life-threatening especially when midodrine is ingested in large doses. Treatment of hypertension depends on symptoms which defines a hypertensive urgency or emergency. A hypertensive emergency is a severe elevation in blood pressure with symptoms of lifethreatening end-organ damage. End-organ damage occurs because of inability for blood vessels to autoregulate and maintain normal perfusion to the tissues by controlling vasoconstriction and vasodilation (7). If the lower or upper limits for autoregulation are exceeded, autoregulation is lost. The autoregulation threshold may be different for patients with chronic disease. Autoregulation loss will affect perfusion to the central nervous system, heart, and kidneys. Neurologic symptoms can result in a hypertensive encephalopathy that includes lethargy, seizure, and coma. Cardiovascular failure with pulmonary edema and renal insufficiency can also occur (8). The goal for treatment of a hypertensive emergency is blood pressure reduction to a safe level preventing further end-organ damage. A rapid reduction in blood pressure may be detrimental due to decreased end-organ perfusion. Immediate reduction of blood pressure by $10-15 \%$ should be targeted. Ongoing antihypertensive therapy should provide a gradual reduction of blood pressure to a safe limit and by no more than $25 \%$ in the first $6-12$ hours $(7,9)$. Ongoing treatment for hypertension should be managed with a continuous IV antihypertensive infusion titrated to regulate blood pressure.

Several different classes of antihypertensive medications are used to control blood pressure during a hypertensive emergency $(7,10)$. There are currently no standardized guidelines on which antihypertensives to use, so antihypertensive agents are chosen based on safety, ease of use and titratability, availability, and onset of action $(7,10)$. IV medications include calcium channel blockers, vasodilators, and beta blockers $(7,8,10)$. 
Nicardipine is a second generation dihydropyridine calcium channel blocker that induces vascular smooth muscle cell relaxation (7). Nicardipine was selected for this patient as a smooth muscle relaxant to counteract the peripheral vasoconstriction of the alpha- 1 agonist effects of midodrine. Nicardipine has a short onset of action within 1-2 minutes and a 3 -hour duration of action $(7,10)$. Nicardipine is commonly used in children because of its favourable safety profile, ease of titration, availability, water solubility, and gradual reduction in blood pressure (8). Nicardipine use is well documented in children and provides consistent blood pressure control $(9,10)$.

Hydralazine is a direct acting arteriolar vasodilator used for hypertensive emergencies. Onset of action occurs within 10 minutes and duration of action is 2-4 hours following a single IV dose $(9,10)$. Hydralazine offers the advantage of intramuscular injection. The delayed response to lowering blood pressure and hypotension that can occur with hydralazine may not be ideal for a patient with a hypertensive emergency (11).

Sodium nitroprusside is a nitrodilator that has been frequently used to control blood pressure because of its rapid onset of action of 1-2 minutes and short half-life of less than 10 minutes. Sodium nitroprusside can cause an abrupt decrease in blood pressure that can be detrimental to patients with a hypertensive emergency. Despite the short duration of action, sodium nitroprusside can be difficult to titrate because of its potent antihypertensive properties. Prolonged infusions can result in thiocyanate and cyanide toxicity, and methemoglobinemia $(9,12)$. Risk increases with duration, amount of drug infused, and impaired hepatic and renal function. Thiocyanate toxicity can be treated with thiosulfate. Thiosulfate added to sodium nitroprusside for infusion can reduce risk of thiocyanate and cyanide toxicity. Cyanide toxicity is treated with thiosulfate or hydroxycobalamine. Methemoglobinemia is treated with methylene blue. Nitroprusside is light sensitive requiring shielding using a light-protective material, like aluminum foil (7).

Beta-blockers such as esmolol and labetalol are frequently used to treat hypertension. Esmolol is a short acting beta 1 -adrenergic blocker with a rapid onset of action and short duration of action of 10 minutes $(7,9,10)$. Esmolol is metabolized by red blood cell esterases therefore the halflife can be prolonged in anemia. Esmolol is contraindicated in hypertension caused by excessive catecholamines because of unopposed alpha stimulation $(9,10)$. IV labetalol is a selective alpha- 1 antagonist and a non-selective beta- 1 and beta-2 blocker. Onset of action is $2-5$ minutes with a longer duration of action of 2-4 hours $(9,10)$. Side effects of betablockers include bradycardia, glucose intolerance, and bronchoconstriction $(7,9,10)$.

Other agents include the IV angiotensin converting enzyme inhibitor enalaprilat. Enalaprilat has been used for renin-angiotensin mediated hypertension $(7,10)$. Enalaprilat can induce acute kidney injury and hyperkalemia. Onset of action is 15 minutes and pharmacologic effects can exceed 6 hours $(9,10)$. Fenoldopam is a selective dopamine-1 agonist that decreases peripheral vascular resistance and increases renal blood flow promoting diuresis and natriuresis $(9,10,13)$. This agent may benefit patients with fluid overload and hypertension and onset of action occurs within 5 minutes $(9,10)$. Phentolamine is a non-selective alpha-blocker that has been used in the management of hypertensive emergencies. Phentolamine may be ideal for drug-induced hypertension with increased circulating catecholamines from sympathomimetic agents. Onset of action is within minutes and duration of action is 15-30 minutes.

\section{Conclusions}

Although midodrine is infrequently used in the pediatric setting, pediatricians, emergency medicine physicians and intensivists should be aware of this uncommon medicine and its adverse effects. Midodrine can cause a significant elevation in blood pressure when taken in large doses resulting in a hypertensive urgency or emergency. It has limited ability to cross the blood-brain barrier in therapeutic doses however significant ingestion can cause severe hypertension with seizures resulting in a hypertensive encephalopathy with cerebral injury with cytotoxic edema. Prompt treatment of hypertension for all patients until the peak of onset of this drug has been reached (3-4 hours) and blood pressure returns to normal is essential.

\section{Acknowledgments}

Funding: None.

\section{Footnote}

Reporting Checklist: The authors have completed the CARE reporting checklist. Available at https://dx.doi. org/10.21037/tp-21-153

Conflicts of Interest: All authors have completed the ICMJE 
uniform disclosure form (available at https://dx.doi. org/10.21037/tp-21-153). EB reports that she serves as the appointed then selected National Society of Pediatric Nurse Practitioners Conference Planning Committee Member and the selected Pediatric Nursing Certification Board Acute Care Exam Item Writer (both of these leadership positions are non-paid positions). Dr. TAN reports that he serves as the elected Council Representative to the Designated Pediatric Seat to the Society of Critical Care Medicine and the Society of Critical Care Medicine liaison to the Organ Donation and Transplantation Alliance Board of Directors (both of these leadership positions are non-paid positions) and receives author royalties from Wolters-Kluwer UpToDate. MJ has no conflicts of interest to declare.

Ethical Statement: The authors are accountable for all aspects of the work in ensuring that questions related to the accuracy or integrity of any part of the work are appropriately investigated and resolved. All procedures performed in studies involving human participants were in accordance with the ethical standards of the institutional and/or national research committee(s) and with the Helsinki Declaration (as revised in 2013). Consent obtained from guardian.

Open Access Statement: This is an Open Access article distributed in accordance with the Creative Commons Attribution-NonCommercial-NoDerivs 4.0 International License (CC BY-NC-ND 4.0), which permits the noncommercial replication and distribution of the article with the strict proviso that no changes or edits are made and the original work is properly cited (including links to both the formal publication through the relevant DOI and the license). See: https://creativecommons.org/licenses/by-nc-nd/4.0/.

\section{References}

1. Izcovich A, González Malla C, Manzotti M, et al. Midodrine for orthostatic hypotension and recurrent reflex syncope: a systematic review. Neurology 2014;83:1170-7.

2. McTavish D, Goa KL. Midodrine. A review of its pharmacological properties and therapeutic use in orthostatic hypotension and secondary hypotensive disorders. Drugs 1989;38:757-77.

3. ProAmatine ${ }^{\circledR}$ (midodrine hydrochloride) Tablets. Available online: https://www.accessdata.fda.gov/drugsatfda_docs/ label/2017/019815s010lbl.pdf

4. Wong LY, Wong A, Robertson T, et al. Severe hypertension and bradycardia secondary to midodrine overdose. J Med Toxicol 2017;13:88-90.

5. Hofer KE, Rauber-Lüthy C, Kupferschmidt H, et al. Acute midodrine overdose: a case series. Clin Toxicol 2012;50:362.

6. Zachariah PK, Bloedow DC, Moyer TP, et al. Pharmacodynamics of midodrine, an antihypotensive agent. Clin Pharmacol Ther 1986;39:586-91.

7. Seeman T, Hamdani G, Mitsnefes M. Hypertensive crisis in children and adolescents. Pediatr Nephrol 2019;34:2523-37.

8. Stein DR, Ferguson MA. Evaluation and treatment of hypertensive crises in children. Integr Blood Press Control 2016;9:49-58

9. Webb TN, Shatat IF, Miyashita Y. Therapy of acute hypertension in hospitalized children and adolescents. Curr Hypertens Rep 2014;16:425.

10. Baracco R. A practical guide to the management of severe hypertension in children. Paediatr Drugs 2020;22:13-20.

11. Flynn JT, Tullus K. Severe hypertension in children and adolescents: pathophysiology and treatment. Pediatr Nephrol 2009;24:1101-12.

12. Holme MR, Sharman T. Sodium Nitroprusside. In: StatPearls. Treasure Island: StatPearls Publishing, 2021. Available online: https://www.ncbi.nlm.nih.gov/books/ NBK557487/

13. Murphy MB, Murray C, Shorten GD. Fenoldopam: a selective peripheral dopamine-receptor agonist for the treatment of severe hypertension. $\mathrm{N}$ Engl J Med 2001;345:1548-57.
Cite this article as: Jan M, Brothers E, Nakagawa TA. Midodrine overdose in children: a case report and review of treatment for hypertensive emergencies. Transl Pediatr 2021;10(9):2398-2401. doi: 10.21037/tp-21-153 